\title{
A thin 43-year-old woman with gross hematuria
}
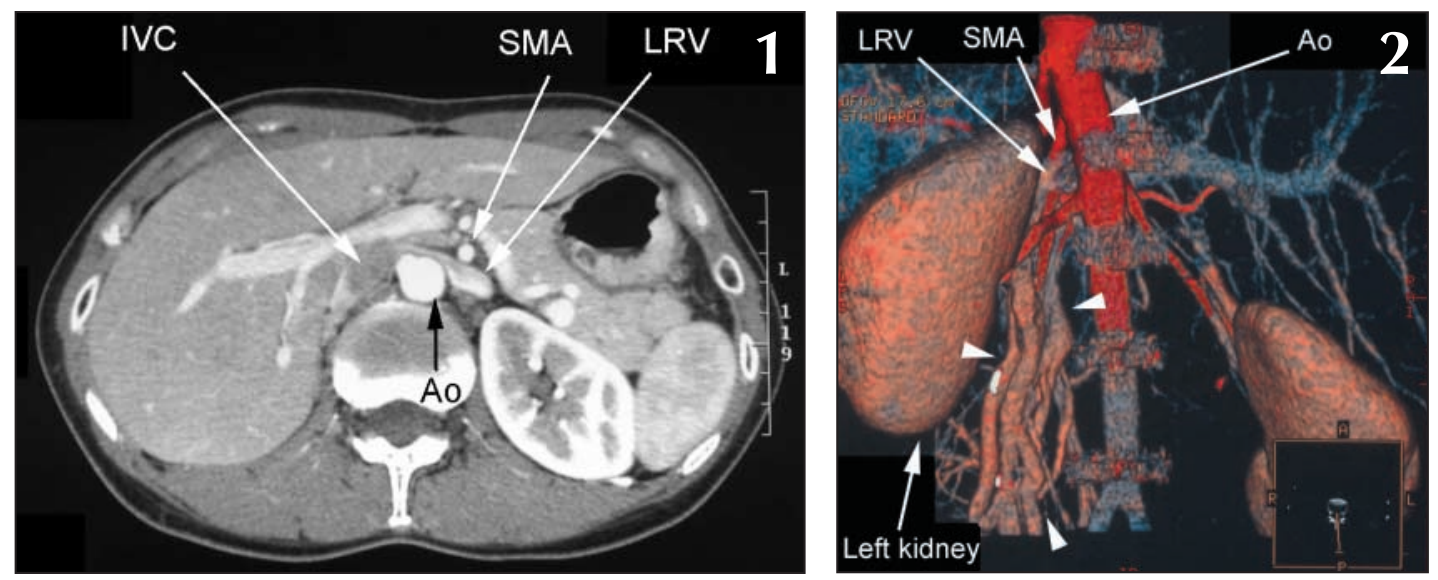

A 43-year-old woman visited our internal medicine service for evaluation of painless gross hematuria of 2 months' duration. She was a nonsmoker with no significant medical history, abdominal trauma or recurrent urinary tract infection. Her body mass index was low $\left(18 \mathrm{~kg} / \mathrm{m}^{2}\right)$. She was afebrile and normotensive, her abdomen and flanks were nontender, and no mass was palpated.

Her complete blood cell count, renal function test results, coagulation profile and immunoglobulin profile were normal. Urinalysis revealed gross hematuria (dipstick test 3+, and numerous erythrocytes per highpower field) without dysmorphic changes, urinary casts or protein, which suggested that the hematuria was of nonglomerular origin. Results of urine culture and cytologic examination were negative. Ultrasonography revealed no abnormalities of the urinary tract. Intravenous pyelography and cystoscopy did not demonstrate any calculus or neoplasm. CT scanning revealed compression of the left renal vein (LRV) between the superior mesenteric artery (SMA) and the abdominal aorta (AO), just distal to where the left renal vein merges into the inferior vena cava (IVC) (Fig. 1). A 3-dimensional helical CT scan (posterior, inferior, left-oblique view) showed the narrowed aortomesenteric angle causing the compression, dilatation of the distal LRV and marked development of collateral veins (Fig. 2, arrowheads), consistent with the "nutcracker" phenomenon. The patient was followed conservatively with routine urinalysis; her hematuria improved spontaneously (dipstick test $1+$ ) a year later.

The nutcracker phenomenon is a rare but important cause of hematuria. ${ }^{1}$ The left renal vein normally passes between the superior mesenteric artery and the aorta; however, in the nutcracker phenomenon, the vein is compressed in the angle created by the 2 arteries, which results in increased venous pressure and the development of collateral veins. Hematuria results when the increased venous pressure causes minute ruptures of the thinwalled septum separating the veins from the collecting system. ${ }^{2}$

One hypothesis for the narrowing of the aortomesenteric angle is a thin body build and decreased amounts of perirenal or mesenteric fat. Other hypotheses include posterior renal ptosis (movable kidney) with stretching of the left renal vein over the aorta, and abnormal branching of the superior mesenteric artery from the aorta. ${ }^{3}$ The prevalence of the phenomenon remains unknown. It usually occurs in adolescents and thin young women.

In addition to hematuria, clinical features may include flank and abdominal pain, orthostatic pro- teinuria, vulvar varices in females, and varicocele in males. The differential diagnosis of nonglomerular hematuria includes urinary tract neoplasms, calculi and infection. The "gold standard" for diagnosis has been invasive angiography and measurement of the renal vein pressure; however, helical CT scanning allows less invasive visualization of vascular branching. Conservative treatment with routine urinalysis has been proposed for mild hematuria, since the development of collateral veins may resolve the hypertension in the left renal vein and alleviate symptoms. Endovascular stenting or surgery (e.g., transposition of the left renal vein and renal autotransplantation) may be indicated for massive hematuria and abdominal pain.

\section{Akira Hokama}

First Department of Internal Medicine Yoshinori Oshiro

Department of Urology

University of the Ryukyus

Okinawa, Japan

\section{References}

1. De Schepper A. "Nutcracker" phenomenon of renal vein causing left renal pathology. 7 Belge Radiol 1972;55: 507-11.

2. Hanna HE, Santella RN, Zawada ET Jr, Masterson TE. Nutcracker syndrome: An underdiagnosed cause for hematuria? S D f Med 1997;50(12): 429-36.

3. Hohenfellner M, Steinbach F, Schultz-Lampel D, Schantzen W, Walter K, Cramer BM, et al. The nutcracker syndrome: new aspects of pathophysiology, diagnosis, and treatment. F Urol 1991;146:685-8. 